\title{
Spatially-explicit water balance implications of carbon capture and sequestration
}

\author{
Roger Sathre ${ }^{1 *}$, Hanna Breunig ${ }^{1,2}$, Jeffery Greenblatt ${ }^{1}$, Peter Larsen ${ }^{1,3}$, Eric Masanet ${ }^{4}$, Thomas McKone $^{1,2}$, Nigel \\ Quinn ${ }^{1}$, Corinne Scown ${ }^{1}$ \\ ${ }^{1}$ Lawrence Berkeley National Laboratory, Berkeley, California, USA \\ ${ }^{2}$ University of California, Berkeley, California, USA \\ ${ }^{3}$ Stanford University, Stanford, California, USA \\ ${ }^{4}$ Northwestern University, Evanston, Illinois, USA \\ * Corresponding author: rsathre@lbl.gov
}

\begin{abstract}
Implementation of carbon capture and sequestration (CCS) will increase water demand due to the cooling water requirements of $\mathrm{CO}_{2}$ capture equipment. If the captured $\mathrm{CO}_{2}$ is injected into saline aquifers for sequestration, brine may be extracted to manage the aquifer pressure, and can be desalinated to provide additional freshwater supply. We conduct a geospatial analysis to determine how CCS may affect local water supply and demand across the contiguous United States. We calculate baseline indices for each county in the year 2005, and project future water supply and demand with and without CCS through 2030. We conduct sensitivity analyses to identify the system parameters that most significantly affect water balance. Water supply changes due to inter-annual variability and projected climate change are overwhelmingly the most significant sources of variation. CCS can have strong local effects on water supply and demand, but overall it has a modest effect on water balances.
\end{abstract}

Keywords: water balance, water stress, CCS, climate change mitigation, GIS, electricity supply

\section{Introduction}

Carbon dioxide $\left(\mathrm{CO}_{2}\right)$ capture and sequestration (CCS) is increasingly discussed as a means to reduce greenhouse gas emissions and limit climate destabilization (IEA 2013, IPCC 2014). The implementation of CCS is expected to have varied effects on local water balances. For example, power plants equipped with $\mathrm{CO}_{2}$ capture will require more cooling water than plants without $\mathrm{CO}_{2}$ capture. Water withdrawal and consumption per $\mathrm{kWh}$ for power plants with $\mathrm{CO}_{2}$ capture could be double that of plants without $\mathrm{CO}_{2}$ capture, and power plant cooling already comprises $49 \%$ of all US water withdrawals (Macknick et al. 2011, Kenny et al 2009). Conversely, if the captured $\mathrm{CO}_{2}$ is injected into saline aquifers for long-term sequestration, brine may need to be extracted from the aquifer to manage the pressure within the geologic formation (Buscheck et al. 2012). The extracted brine may be desalinated and used as a freshwater resource, partially offsetting the increased water demand for power plant cooling. 
CCS must be implemented on a very large scale to contribute significantly to climate change mitigation, (Herzog 2011). To avoid unintended consequences from deployment of CCS, decision-makers must consider its interrelations with water use (Sathre et al. 2012). Water stress varies geographically-both within the United States (US) and globally. Areas with greater water stress may be less suited for expansion of water-intensive activities such as electricity production and $\mathrm{CO}_{2}$ capture. Water supply and

demand also vary over different time scales, as technologies and behaviors change. Spatially and temporally dynamic factors that affect a region's water balance include demand from agriculture, industry, and domestic consumption; demand for electricity and the share of electricity produced by fossil fuels and other sources; the rate and extent of CCS deployment; potential extraction of brine to manage pressure in saline aquifers used for $\mathrm{CO}_{2}$ sequestration; and the effects of climate change on water supply patterns.

Prior literature provides partial insight into the local relationships between CCS implementation and water supply and demand. NETL (2010b) estimated the increased aggregate water use due to several projected CCS deployment scenarios in the US through 2035, though provided no breakdown by geographic region, which is critical to understanding local water supply and demand. Tidwell et al. (2013) analyzed the water use implications of CCS retrofitting in water-stressed regions of the US. They showed that water consumption could increase by almost 1 million $\mathrm{m}^{3}$ day $^{-1}$, but did not consider the potential additional water supply from brine extracted from saline reservoirs. Talati et al. (2014) examined the change in overall water use that would result from proposed $\mathrm{CO}_{2}$ emission standards in the US, finding significant differences in water use between power plants using different fuels, cooling systems, and $\mathrm{CO}_{2}$ capture percentages. However, they provided no information on regional differences, potential local water constraints, or water supply from extracted brine. Schakel et al. (2015) studied the effect of CCS deployment on water stress in Europe, finding potentially significant impacts by 2050 in some areas including the UK, Spain, and central and eastern Europe.

In this analysis, we explore how CCS implementation in the electrical power sector may affect the balance of water supply and demand in the US. We conduct a spatially-explicit analysis at the US county level to understand regional variations in water supply and water demand. Given the dynamic nature of the system across temporal and spatial dimensions, we explore how potential variations in local water balances due to CCS (resulting from both increased cooling water demand and brine availability) compare with other sources of variability such as climate change, population change, and water demand in other sectors. This analysis allows us to identify the main drivers of uncertainty and variability within the system, and begin to define the solution space of possible outcomes.

\section{Methods}

\subsection{Modeling framework}

We develop and apply a spatially explicit system model of current and projected water supply and demand. The geographic scope of the analysis is the contiguous US, with spatial resolution at the county level (identified using 3,109 Federal Information Processing Standard (FIPS) codes). The temporal scope includes a baseline analysis of 2005 conditions, as well as scenario projections to 2030 to identify potential future water-related implications of CCS deployment. We analyze the local interactions between CCS deployment, water supply and water demand. On the demand side, we compare the magnitude of water flows associated with CCS to the water requirements of other sectors such as irrigation, industry and public water supply. On the supply side, we use water supply projections and saline aquifer characteristics to estimate potential water availability. We determine how scenario conditions and system 
parameters affect the water balance and water stress of each county through 2030 . The modeling framework is shown schematically in Figure 1.

Water supply (WS)

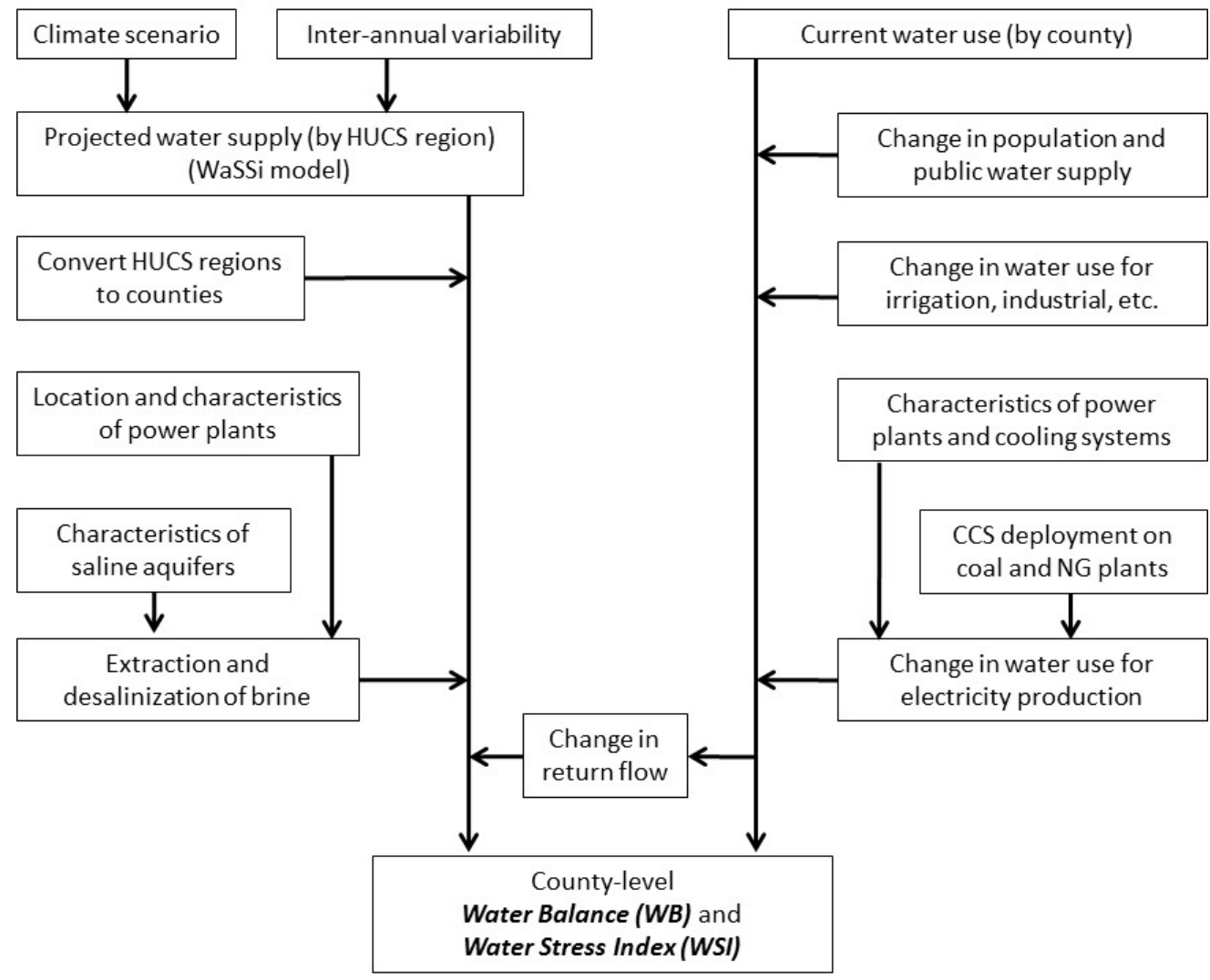

Figure 1. Schematic diagram of the system modeling framework.

We analyze the water flows within each county under three scenarios: (1) no CCS implementation; (2) CCS deployment without brine extraction; and (3) CCS deployment coupled with brine extraction and desalination. The water balance implications of CCS deployment are estimated based on prospective mass and energy flow modeling of fossil fuel-fired electricity generation systems with and without CCS integration. An example of the modeling output is shown in Figure 2, which describes selected mass and energy flows associated with the operation of an illustrative $500 \mathrm{MW}$ coal-fired power plant equipped with CCS for one minute. This example figure serves to illustrate the interactions between energy systems and water supply and demand. In our analysis, each individual case is quantitatively modeled based on the unique characteristics of the power plant and saline aquifer, as described below. 


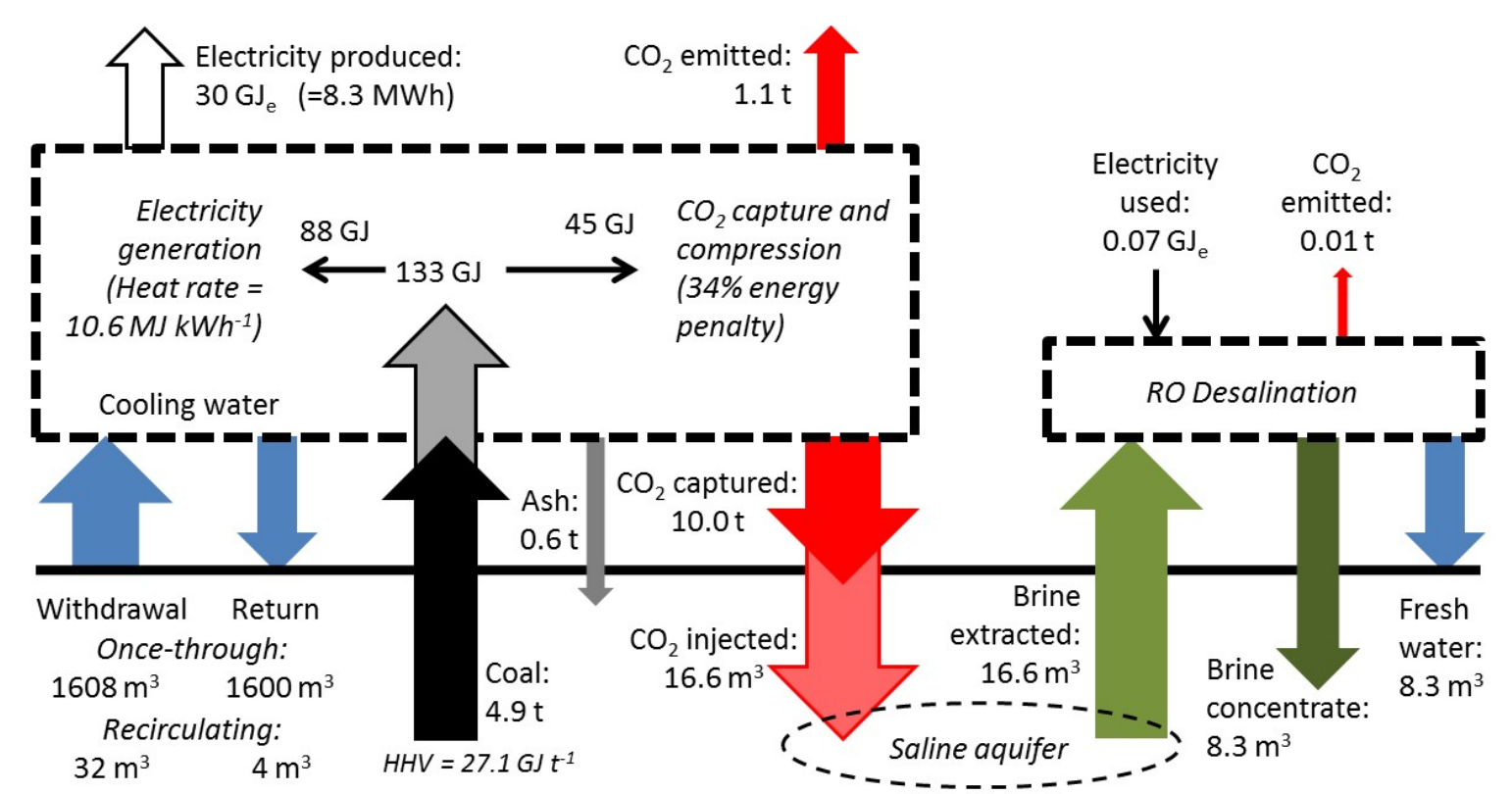

Figure 2. Selected mass and energy flows associated with the operation of an illustrative 500 MW power plant with CCS for one minute. The dashed box on the left is the power plant with $\mathrm{CO}_{2}$ capture, the dashed box on the right is the RO desalination plant, and the horizontal line is the earth's surface.

\subsection{Water supply}

County-level freshwater supply $(W S)$ is calculated as:

$$
W S=W S W a S S i+\Delta W S b r i n e+\Delta W S r e t u r n
$$

where $W S_{\text {WaSSi }}$ is the projected county-level groundwater and surface water supply for a given climate scenario based on the WaSSi model, $\Delta W S_{\text {brine }}$ is the change in county-level water supply due to brine extraction and desalination, and $\Delta W S_{\text {return }}$ is the change in county-level water supply due to altered water return flows as a consequence of changes in water demand. WS is calculated in units of $\mathrm{m}^{3} \mathrm{day}^{-1}$.

Local water supply projections are based largely on the WaSSi model (Sun et al. 2008). The WaSSi model estimates local water supplies at the level of US Geologic Survey (USGS) 8-digit Hydrologic Unit Code (HUC) watershed regions. Water supply for each HUC region is the sum of surface water supply, groundwater supply, and return flows. Surface water supply is estimated using a hydrological water balance model that predicts water supply as a function of monthly precipitation received, potential evapotranspiration, land use type, canopy interception capacity, soil moisture content, and plant rooting depth (Zhou et al. 2008). Groundwater supply is based on historical annual groundwater withdrawal records from the USGS. Return flow is based on historical return flow rates (Solley et al. 1998) multiplied by water use in different sectors such as domestic, industrial, irrigation, and thermoelectric power generation.

Future water supply varies according to climate change projections, based on emission scenarios from the IPCC Special Report on Emissions Scenarios (SRES) (IPCC 2000). Climate change projections in the WaSSi model are based on downscaled climate modeling by Coulson et al. (2010) comprising monthly precipitation, monthly means of daily maximum air temperature, and monthly means of daily minimum air temperature. Our base-case climate projection uses the SRES B2 emission scenario, while the projected climate change associated with the SRES A1B emission scenario is also analyzed in a 
sensitivity analysis. The WaSSi model uses data from the MK2 climate model of Australia's Commonwealth Scientific and Industrial Research Organisation (CSIRO). We consider a nine-year window around the nominal analysis year (i.e., the four preceding years, the nominal year, and the four following years) to incorporate the effects of inter-annual variability in water supply. The "average annual water supply" and the "minimum annual water supply" for the nine-year span are used in water balance calculations. Intra-annual (e.g. seasonal) variability is not considered in this analysis.

The geographic resolution of WaSSi water supply data is HUC watershed regions, while the water demand analysis is resolved into political county regions (FIPS regions). Accordingly, we intersect two national scale geographic information system (GIS) map coverages, one comprised of 3,109 FIPS regions and the other comprised of 2,106 HUC regions. ArcGIS software is used to first re-project the county coverage so that both county and HUC coverages are in the same coordinate system. The HUC and county coverages are combined in a single feature resulting in more than 15,000 separate polygons, and the area of these polygons is calculated. Analysis is limited to HUC polygons larger than $10 \mathrm{~km}^{2}$ that lie within a given county, in order to reduce the number of polygons to a manageable number. Because the average area of a county in the contiguous US is $2572 \mathrm{~km}^{2}$, we expect the error introduced by this simplification will be minimal. The proportion of each HUC that lies within a particular county is calculated by dividing HUC area by county area. A matrix is then created to allow the conversion of water supply at the HUC level to approximate water supply at the county level, based on the proportion of coinciding land area in each.

An additional potential source of freshwater is desalination of brine extracted from saline aquifers used for $\mathrm{CO}_{2}$ sequestration. Locations of saline aquifers in the US are based on the NATCARB GIS database (NETL 2012). Aquifers are included that underwent an initial site screening step by NATCARB; these aquifers have been assessed for storage potential and are listed by NATCARB as possible candidates for use in geologic $\mathrm{CO}_{2}$ injection. Additional screening, selection, and characterization is necessary to ensure aquifers meet technical and non-technical criteria, however NATCARB limits its initial screening to the geological criteria of capacity, injectivity, and integrity. Storage capacity is estimated based on the pore volume that can be occupied by injected $\mathrm{CO}_{2}$. Formations that store supercritical $\mathrm{CO}_{2}$, which has a critical point of $32{ }^{\circ} \mathrm{C}$ and $7.4 \mathrm{MPa}$, reside at different depths due to thermal and hydrodynamic conditions, but typically occur between depths of 800 and 3000m (Bachu et al. 2003; NETL 2010a). We characterize the total dissolved solids (TDS) concentrations within the aquifer using USGS data on produced water sampled at appropriate depths.

A review of CCS life cycle assessments found that reference distances for pipeline transportation of $\mathrm{CO}_{2}$ ranged from 50 to $500 \mathrm{~km}$ (Corsten et al. 2013). While distances upward of $500 \mathrm{~km}$ have been reported for Norwegian projects directing $\mathrm{CO}_{2}$ to oil and gas fields for enhanced recovery (Khoo and Tan 2006), it is unlikely that the storage of $\mathrm{CO}_{2}$ in saline aquifers would warrant such distances since there is no monetary incentive. Hasan et al. (2014) used an upper bound of 200 miles (322 km) in their supply chain network optimization model of $\mathrm{CO}_{2}$ utilization options, including enhanced oil recovery, arguing that pipeline lengths greater than this were unlikely to be a part of the most economical supply chains in the United States. In our base-case analysis we limit CCS deployment to counties within $100 \mathrm{~km}$ of a suitable aquifer, beyond which we do not consider CCS as an option for power plants located in the county. We consider this appropriate for sequestration in saline aquifers where there is no enhanced fuel recovery to offset transportation costs. To determine the significance of this parameter, we also consider threshold distances of $25 \mathrm{~km}$ and $250 \mathrm{~km}$ in a sensitivity analysis. We use spatial analysis tools in ArcGIS software to determine the distance from the nearest region of a suitable saline aquifer to a county's center point. Figure 3 shows the counties that are within $25 \mathrm{~km}, 100 \mathrm{~km}$, and $250 \mathrm{~km}$ from a suitable aquifer. 


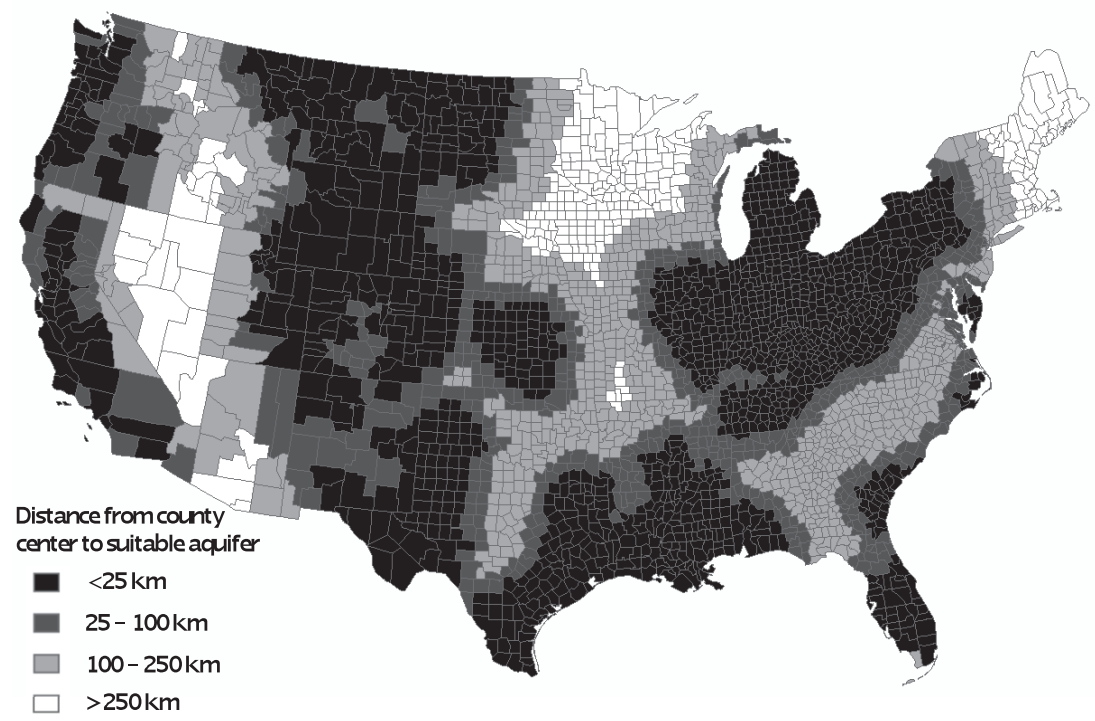

Figure 3. Distance from the center of each county to the edge of the nearest saline aquifer suitable for $\mathrm{CO}_{2}$ sequestration.

To estimate quantities of extracted brine, we assume a density of supercritical $\mathrm{CO}_{2}$ of $0.60 \mathrm{t} \mathrm{m}^{-3}$, and we assume a brine-to- $\mathrm{CO}_{2}$ displacement ratio of 1:1 by volume; in other words, for each $\mathrm{m}^{3}$ of supercritical $\mathrm{CO}_{2}$ injected into a saline aquifer, $1 \mathrm{~m}^{3}$ of brine is extracted (Buscheck et al. 2012). A brine-to- $\mathrm{CO}_{2}$ displacement ratio of $0.5: 1$ is also explored in a sensitivity analysis. The salinity of the extracted brine, measured as TDS, limits the fraction of freshwater that can be produced via reverse osmosis (RO) desalination. In our desalination analysis, we adapt data from Bourcier et al. (2011) and Aines et al. (2011) and assume that brines with TDS greater than $100 \mathrm{~g} \mathrm{~L}^{-1}$ cannot be treated by standard RO. We make a conservative assumption that brines with TDS less than $50 \mathrm{~g} \mathrm{~L}^{-1}$ can be treated with a $50 \%$ recovery fraction of freshwater, meaning that for every $2 \mathrm{~L}$ of brine treated, $1 \mathrm{~L}$ of freshwater and $1 \mathrm{~L}$ of concentrated brine are produced. For brines with TDS less than $100 \mathrm{~g} \mathrm{~L}^{-1}$ and greater than $50 \mathrm{~g} \mathrm{~L}^{-1}$ we use Equation 2 to determine the recovery fraction:

$$
\text { Recovery Percent }=1-T D S 100 \mathrm{~g} / \mathrm{L} \times 100 \%
$$

where Recovery Percent is the maximum recovery fraction achievable using current RO technology, and $[T D S]$ is the average TDS concentration of brine sampled in an aquifer. This equation reflects current RO membrane thresholds for osmotic pressure (Bourcier et al. 2011). It implies, for example, that brine with TDS of $80 \mathrm{~g} \mathrm{~L}^{-1}$ can be treated with a $20 \%$ freshwater recovery fraction. We assume that the concentrated brine produced by the desalination process is disposed of in a manner that does not affect the freshwater balance, e.g., by reinjection. For each county, quantities of freshwater recovered from brine desalination are added to quantities of other freshwater from the WaSSi model to determine the total water supply.

\subsection{Water demand}

County-level freshwater demand $(W D)$ is calculated as:

$$
W D=W D \text { current }+\Delta W \text { Delectricity }+\Delta W D \text { population }+\Delta W D \text { other }
$$

where $W D_{\text {current }}$ is the latest available actual county-level water demand, $\Delta W D_{\text {electricity }}$ is the change in water demand due to thermoelectric power plant deployment with and without CCS, $\Delta W D_{\text {population }}$ is the 
change in county-level public and self-supplied domestic water demand due to projected population change, and $\Delta W D_{\text {other }}$ is the change in water demand due to projected changes in water use for irrigation, industrial, livestock, aquaculture and mining. $W D$ is calculated in units of $\mathrm{m}^{3}$ day $^{-1}$.

Annual water use in 2005 within each county is based on USGS data describing water withdrawals in 2005 for public supply, self-supplied domestic use, irrigation, livestock, aquaculture, industrial, and mining (Kenny et al. 2009). The USGS report also includes coarse data on water used for thermoelectric power generation, though we choose to instead use power plant data from Ventyx (2012), as described below, due to its greater granularity. In 2005, water withdrawals in the US averaged approximately 1.5 billion $\mathrm{m}^{3}$ per day (Kenny et al. 2009). Domestic and commercial uses made up only $12 \%$ of total US withdrawals. The sectors responsible for the majority of water use are thermoelectric power generation and agriculture, contributing $49 \%$ and $31 \%$ of total water withdrawals, respectively. Other sectors contribute smaller fractions, including industrial facilities (4\%), aquaculture (2\%), mining (1\%), and livestock $(<1 \%)$ (Kenny et al. 2009).

We adapt the 2005 annual data to account for projected future changes in county-level water use by 2030 . Exploring how water use in various sectors has changed in recent history and the factors driving those changes may offer insight into how water demand will evolve in the coming decades. Between 1950 and 1980 , total US water withdrawals grew at a rate that significantly outpaced population growth, peaking at 1.6 trillion liters per day. More recently, however, water use intensity (measured, for example, in $\mathrm{m}^{3}$ of water per unit of economic output) has decreased steadily in most sectors (Brown 2000). This has resulted in total water use remaining fairly stable despite increased economic activity. For example, water resource limitations and federal regulations resulted in increased use of recirculating cooling systems for power plants, which withdraw only about $3 \%$ of the water used in once-through cooling systems, per unit of power output (Macknick et al. 2011). Industrial water use has been similarly impacted. Because water is often used to transfer heat within an industrial facility and remove waste heat, energy efficiency improvements provide the indirect benefit of reducing water requirements (Ellis et al. 2001). The result of these changes has been an overall decrease in US water withdrawals since 1980, despite increasing population and economic activity.

For water used for public supply and self-supplied domestic use in 2030, we estimate changes based on population and per capita water use. County population projections are based on Zarnoch et al. (2010) who developed three sets of population growth projections (low, medium, and high). We use the medium growth projection in our base-case modeling, and the low and high growth projections in a sensitivity analysis. Our base-case scenario assumes that per capita water use remains constant, thus county-level water use varies linearly with changes in county population; in a sensitivity analysis we consider the effects of a $20 \%$ increase in per capita water use. Our base case further assumes that county-level water use for irrigation, livestock, aquaculture, industrial, and mining purposes remain constant, based on past trends of water-use efficiency (Brown 2000, Kenny et al. 2009). To determine the significance of changes in water use in these sectors, we increase water use in each of these sectors by $20 \%$ in a sensitivity analysis.

To estimate the current and future water use in the thermoelectric power sector, we develop a dataset of coal- and natural gas-fired power plants in the contiguous US, based primarily on Ventyx (2012) data. The dataset includes all power plants that emitted at least $100,000 \mathrm{t} \mathrm{CO}_{2}$ in 2005. Carbon capture is less economically feasible at scales smaller than this plant size (IPCC 2005). In total, 757 power plants are included, of which 355 are fueled by coal and 402 are fueled by natural gas. Collectively, the coal-fired plants produced a total of 1,826 TWh of electricity and emitted 1,785 $\mathrm{Mt}$ of $\mathrm{CO}_{2}$ in 2005, for an average emission intensity of $0.98 \mathrm{tCO}_{2} \mathrm{MWh}^{-1}$ The gas-fired plants collectively produced a total of $683 \mathrm{TWh}$ of electricity and emitted $384 \mathrm{Mt}$ of $\mathrm{CO}_{2}$ in 2005 , for an average emission intensity of $0.56 \mathrm{tCO}_{2} \mathrm{MWh}^{-1}$. We assume future power generation will be located at the same sites, due to infrastructural inertia within the 
sector. Modeled future changes in overall electricity production are based on Annual Energy Outlook (AEO) regional projections for 2030 (EIA 2011). We scale the current electricity production in each county in proportion to the AEO projections for the NERC region the county is in, for both coal- and gasfired production.

We develop a set of criteria for determining which of the 757 power plants are suitable for retrofitting with $\mathrm{CO}_{2}$ capture equipment (MIT 2009; IEA 2012). Plants that satisfy all of the following four criteria are deemed suitable:

1. nameplate generating capacity of $200 \mathrm{MW}$ or more;

2. capacity factor in 2005 of $50 \%$ or greater (capacity factor of a power plant is defined as the total amount of electricity produced during a period of time, divided by the amount of electricity the plant would have produced if operated continuously at full capacity);

3. average heat rate of $12.7 \mathrm{MJ} \mathrm{kWh}^{-1}$ or less (heat rate of a power plant is defined as the heat value of fuel required to produce a unit of electricity);

4. construction year of 1960 or later.

The first criterion is due to the economy of scale of CCS installations, making larger power plants more attractive than smaller ones. The second is because $\mathrm{CO}_{2}$ capture facilities are best operated continuously, rather than intermittently. The third restricts CCS retrofitting to more efficient power plants, which can best benefit from the investment. The fourth criterion removes older power plants from retrofitting consideration, because they are close to retirement age.

Of the total number of 355 coal-fired plants, 288 have adequate nameplate capacities, 286 have adequate capacity factors, 292 have adequate heat rates, 238 were built in 1960 or later, and 168 plants meet all four criteria for CCS retrofitting. Of the 402 gas-fired plants, 349 have adequate nameplate capacities, 84 have adequate capacity factors, 336 have adequate heat rates, 349 were built in 1960 or later, and 49 plants meet all four criteria. Thus, a total of 217 plants meet all criteria for CCS retrofitting, of which 168 are coal-fueled and 49 are natural gas-fueled. Collectively these plants emitted about $1350 \mathrm{Mt}^{-\mathrm{CO}_{2}}$ in 2005 , or about $62 \%$ of total emissions from all 757 plants. Figure 4 shows the locations and $\mathrm{CO}_{2}$ emissions of these power plants. In addition to these plant-level criteria, the distance from the county to the nearest suitable sequestration formation (Figure 3) also determines suitability for $\mathrm{CO}_{2}$ capture in any given plant. A total of 141 power plants meet all four plant-level criteria for CCS retrofitting and are within $100 \mathrm{~km}$ from a suitable aquifer; these plants emitted about $1025 \mathrm{Mt}$ of $\mathrm{CO}_{2}$ in 2005. 


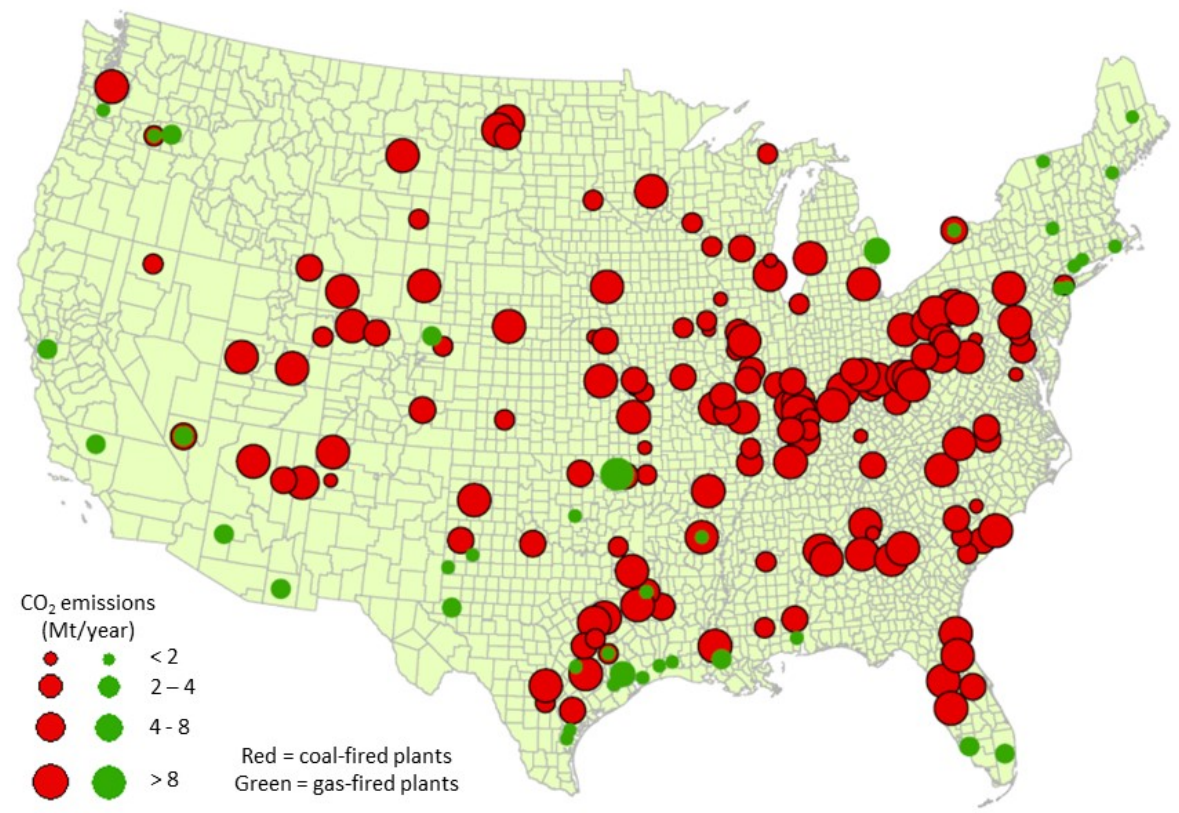

Figure 4. Locations of 217 coal-fired (red) and natural gas-fired (green) power plants that meet plant-level criteria for $\mathrm{CO}_{2}$ capture retrofitting. Size of circle corresponds to amount of $\mathrm{CO}_{2}$ emission in 2005.

These selection criteria are relaxed in a sensitivity analysis to determine the significance of a greater number of retrofitted plants, including all plants larger than $100 \mathrm{MW}$ nameplate capacity (instead of 200 MW), with a capacity factor greater than $40 \%$ (instead of $50 \%$ ), a heat rate less than $13.7 \mathrm{MJ} \mathrm{kWh}^{-1}$ (instead of $12.7 \mathrm{MJ} \mathrm{kWh}^{-1}$ ), and built after 1955 (instead of 1960). Under these less stringent criteria, an additional 69 coal-fired plants and 51 gas-fired plants can be retrofitted.

Our power plant dataset also includes information on types of plant cooling systems, such as rates of water withdrawal, discharge, and consumption, and the source of the cooling water (Ventyx 2012). Cooling system data for 2005 are available for plants responsible for $94 \%$ of the total $\mathrm{CO}_{2}$ emissions. 2005 cooling system data are not available for the remaining plants, so we use USGS data for plants responsible for $4 \%$ of $\mathrm{CO}_{2}$ emissions and proxy average cooling data for the remaining $2 \%$ of plants. We assume that water withdrawals per $\mathrm{kWh}$ for plant cooling will increase by $80 \%$ when $\mathrm{CO}_{2}$ capture equipment is installed based on Zhai et al. (2011), which is broadly consistent with the findings of Macknick et al. (2011). We further assume that the CCS energy penalty, defined as the percent increase in fuel input per unit of delivered electricity, is 35\% (Sathre et al. 2011). The cooling water increase and the energy penalty are varied in a sensitivity analysis. The total $\mathrm{CO}_{2}$ production changes proportionally with the fuel use, and we assume that $90 \%$ of the $\mathrm{CO}_{2}$ in the flue gas is captured and sequestered. Water use by nuclear power plants is assumed to remain unchanged. Water use by power plants that use saline cooling water is not accounted for in the analysis.

A portion of all increased water use is assumed to return to the hydrologic system for further use. This return flow amount is based on Solley et al. (1998) and is $80.8 \%$ for public supply and self-supplied domestic water, $85.2 \%$ for self-supplied industrial water, $39.3 \%$ for irrigation, livestock and aquacultural water, $85.2 \%$ for mining water, and $97.5 \%$ for thermoelectric cooling water. These return water flows are included as a water supply component in Equation 1.

\subsection{Water Balance and Water Stress Index}


For each county under each scenario we calculate the freshwater balance, which we define as:

$$
W B=W S-W D
$$

where $W B$ is the water balance, $W S$ is the water supply, and $W D$ is the water demand.

Following the approach developed by Sun et al. (2008), we also calculate a Water Stress Index (WSI) defined as:

$$
W S I=W D W S
$$

The WSI is dimensionless, and is the ratio of county-level freshwater demand and freshwater supply. A lower value implies less water stress while a higher value implies greater water stress. A WSI of unity means all available freshwater is used; a value greater than unity implies that water is imported into the region from outside sources.

\section{Results}

Figure 5 shows the 2005 WSI for US counties, considering average annual water supply and minimum annual water supply. Not surprisingly, water stress is higher in the minimum annual water supply scenario. The area most critically affected by water stress is the desert southwest US, but highly populated counties in other regions also experience local water stress. Comparison between Figures 4 and 5 show that many isolated cases of high water stress are likely due to cooling water use by thermoelectric power plants.
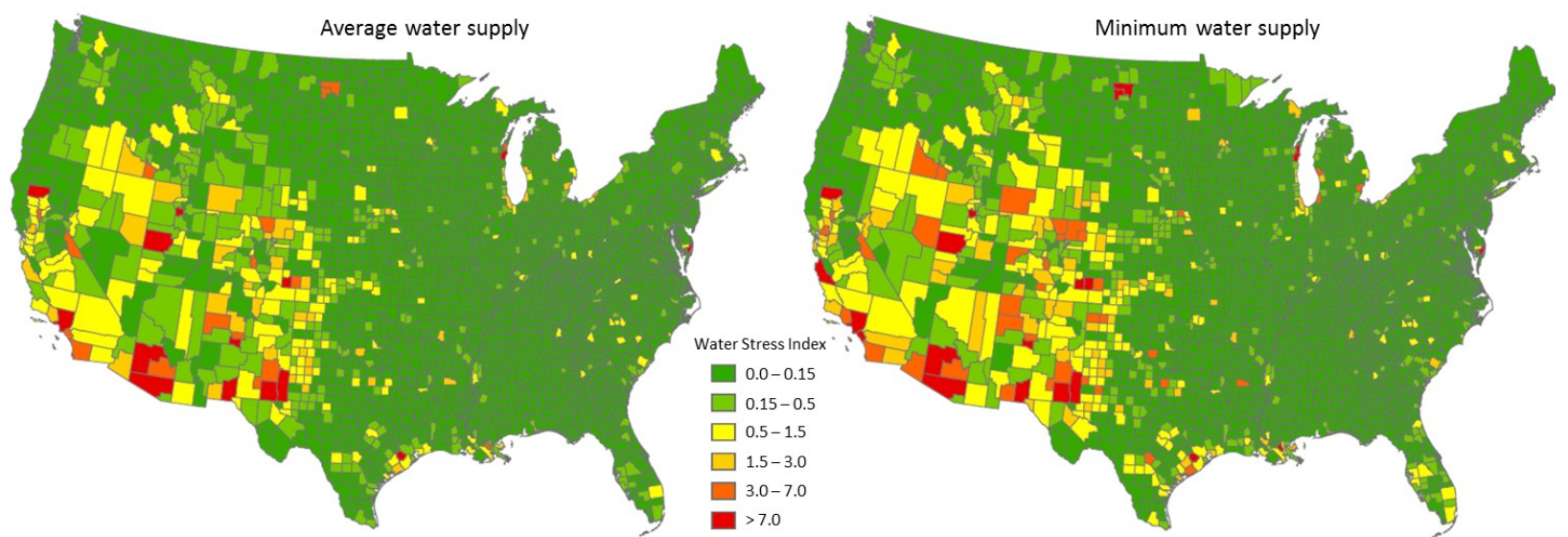

Figure 5. Water Stress Index for counties in 2005, with average annual water supply (left) and minimum annual water supply (right).

Figure 6 shows the projected WSI for all counties in 2030 with average and minimum annual water supplies, not including the effects of CCS implementation. Overall, the projected future changes in water stress through 2030 are modest. There are some cases of increased water stress, particularly in the southwest. Increased water stress is more commonly seen in years of minimum water supply. There are also several counties in which the WSI is projected to decrease by 2030. 


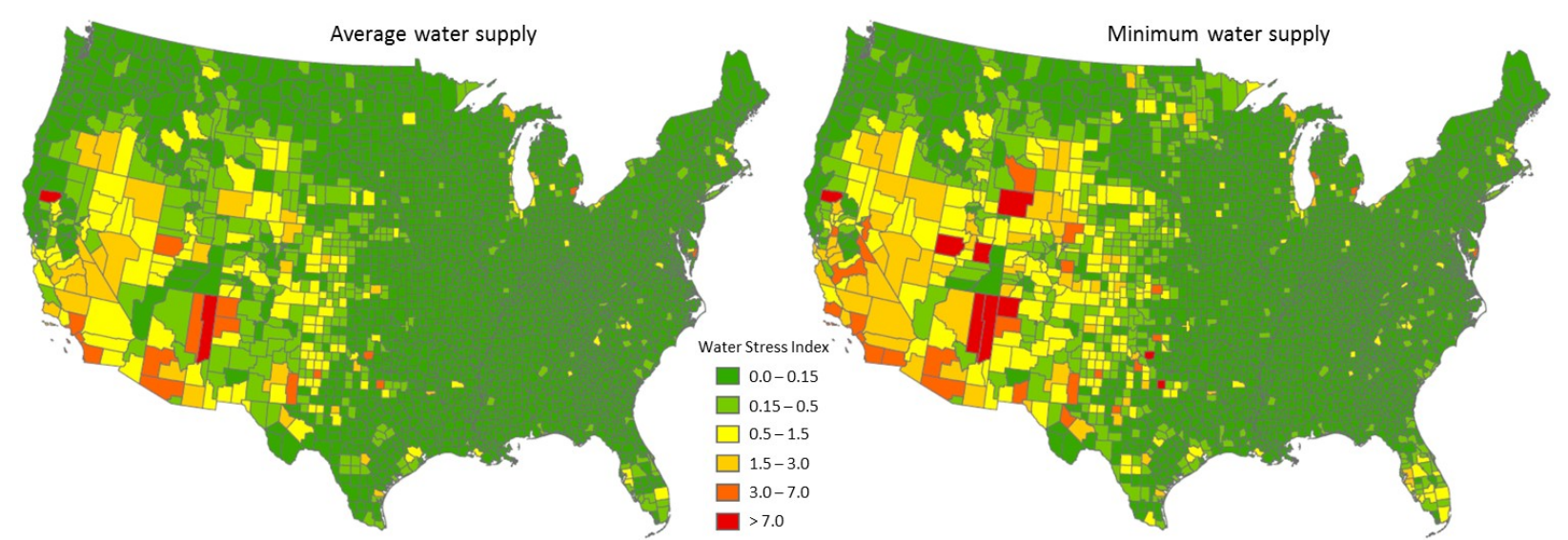

Figure 6. Water Stress Index for counties in 2030 with no CCS implementation, with average annual water supply (left) and minimum annual water supply (right).

Figure 7 shows the increase in WSI due to the additional water use for the implementation of CCS, not including brine extraction and desalination, in counties in 2030 under average and minimum annual water supply conditions. There are several counties, primarily in the southwest, that may experience significant local water stress due the implementation of CCS. This effect is more pronounced under conditions of minimum water supply.
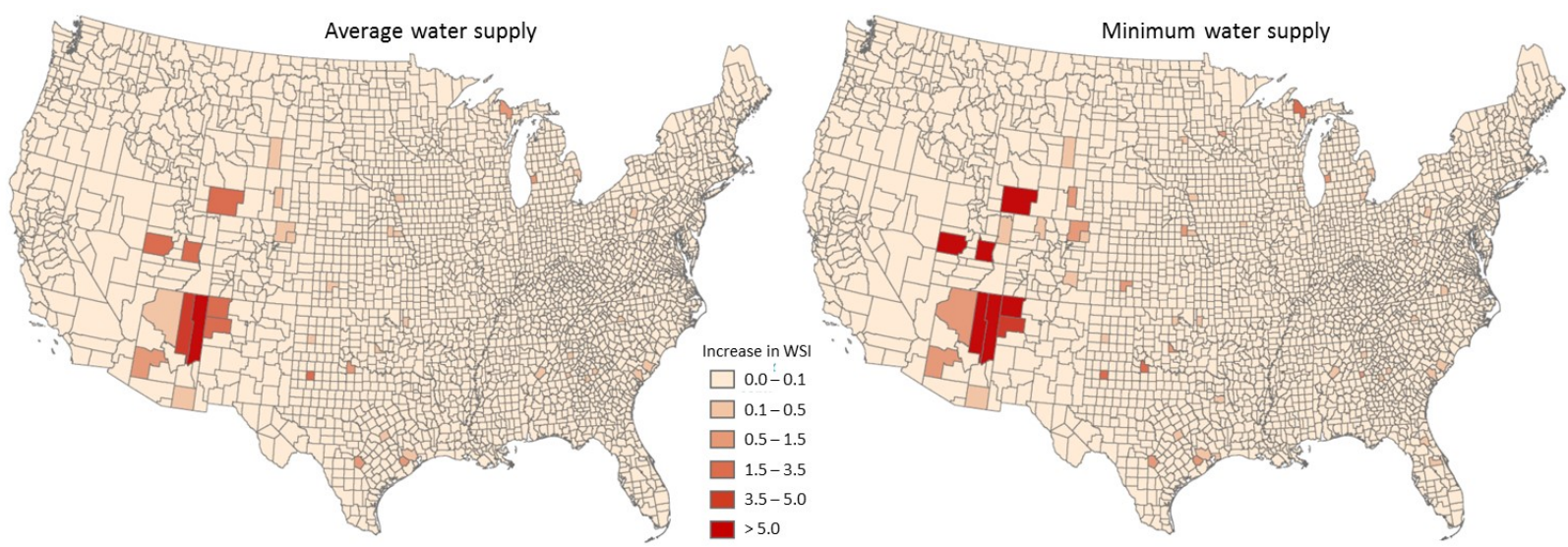

Figure 7. Increase in Water Stress Index for counties in 2030 due to implementation of CCS without brine extraction and desalination.

Figure 8 shows the reduction of WSI due to the additional water supply from brine extraction and desalination, relative to CCS use without brine extraction, in counties in 2030 under average and minimum annual water supply conditions. The additional freshwater available from extraction and desalination of brine is shown to have a greater impact on WSI under conditions of minimum water supply. In absolute terms, the change in WSI due to brine extraction is less than the change due to CCS implementation. 


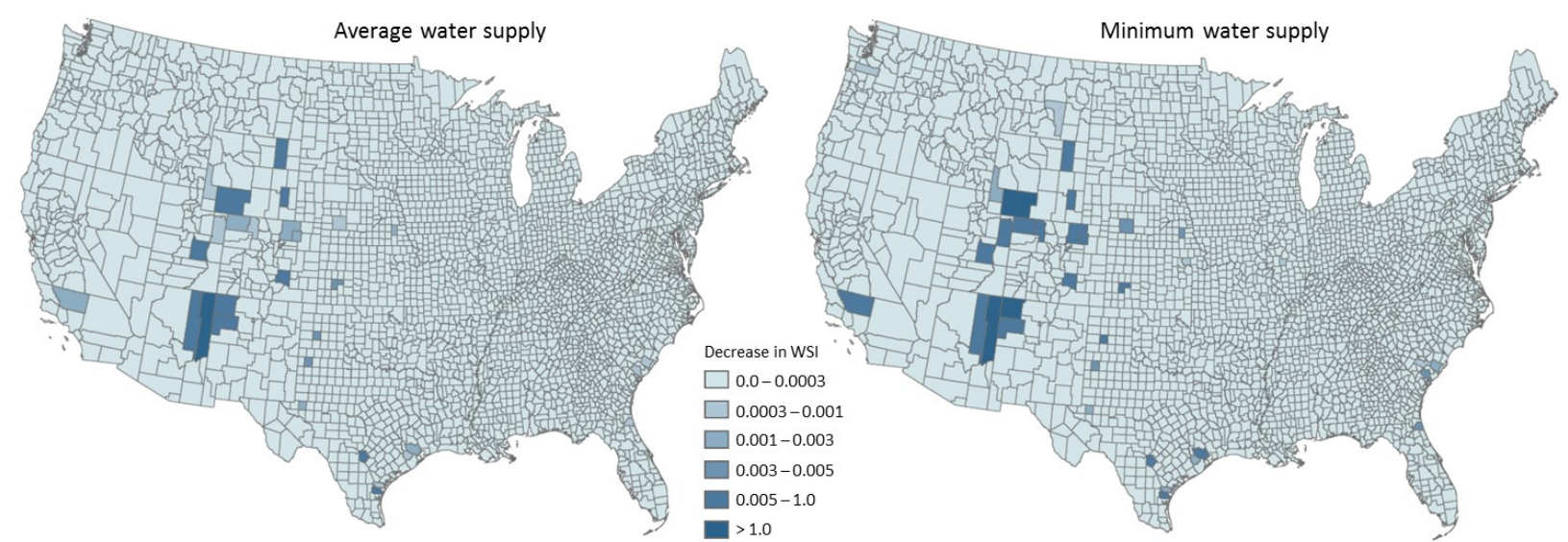

Figure 8. Decrease in Water Stress Index for counties in 2030 due to brine extraction and desalination (relative to WSI of CCS without brine extraction).

Table 1 lists the results of a sensitivity analysis of various system parameters. Four indicators are quantified for each change in parameter value: nationwide water balance $\left(\mathrm{km}^{3}\right.$ day $\left.{ }^{-1}\right)$, defined as the total water supply minus the total water demand; nationwide mean and median of Water Stress Indices of all counties; and the number of counties with WSI greater than 1.

The largest source of variation in water stress, by far, is natural variability in water supply between years of average precipitation and minimum precipitation. Years of minimum precipitation have a national total water balance that is one-third lower than average years, with more than double the number of counties with WSI greater than 1 . Another important source of variation is the extent of future climate change. Altering the climate change projection from the IPCC SRES B2 (i.e., the base case) to the A1B emission scenario results in a significant increase in water balance. This is due to the difference in future climate patterns between the scenarios, with the A1B scenario having higher average precipitation.

Changing the water use for irrigation has a moderately large effect, followed by the per capita water use of public and domestic supplies. Population growth rate, CCS energy penalty, and variation in water use for livestock, aquaculture, and industrial purposes have little impact on the system indicators. Broadening the criteria for which plants are retrofitted with $\mathrm{CO}_{2}$ capture equipment results in a modest decrease in water balance and increase in water stress. The allowable distance between the power plant location and the geological sequestration formation is found to be less significant. At our base-case threshold of 100 $\mathrm{km}, \mathrm{CO}_{2}$ capture can be implemented at 141 of the 217 plants that meet the technical criteria established for suitability for retrofitting. If the maximum distance to an aquifer is extended to $250 \mathrm{~km}, \mathrm{CO}_{2}$ capture can occur at 179 plants. At a threshold distance of $25 \mathrm{~km}, \mathrm{CO}_{2}$ capture can occur at only 112 of the plants. 
Table 1. Values of key indicators under base-case conditions, and change from base case due to variation of one parameter at a time.

\begin{tabular}{|c|c|c|c|c|c|c|}
\hline \multirow{2}{*}{ Parameter } & \multirow{2}{*}{$\begin{array}{l}\text { Base-case } \\
\text { parameter value }\end{array}$} & \multirow{2}{*}{$\begin{array}{l}\text { Adjusted } \\
\text { parameter value }\end{array}$} & \multirow{2}{*}{$\begin{array}{r}\text { Water } \\
\text { balance } \\
\left(\mathrm{km}^{3} / \text { day }\right)\end{array}$} & \multicolumn{2}{|c|}{ Water Stress Index } & \multirow{2}{*}{$\begin{array}{r}\text { Number of } \\
\text { counties with } \\
\text { WSI }>1\end{array}$} \\
\hline & & & & Mean & Median & \\
\hline Base-case & See below & $\mathbf{N} / \mathbf{A}$ & 95.040 & 0.117 & 0.0081 & 75 \\
\hline \multicolumn{7}{|c|}{ Change from base case due to variation of each parameter: } \\
\hline Annual precipitation & Average & Minimum & -34.9571 & +0.09255 & +0.00723 & +89 \\
\hline Climate change scenario & SRES B2 & SRES A1B & +4.6167 & -0.02696 & -0.00112 & -23 \\
\hline Irrigation use & Unchanged & $+20 \%$ & -0.0686 & +0.00362 & +0.00022 & +9 \\
\hline Per capita public and domestic use & Unchanged & $+20 \%$ & -0.0099 & +0.00110 & +0.00073 & 0 \\
\hline CCS deployment & Yes & No & +0.0092 & -0.00833 & -0.00013 & 0 \\
\hline Plants retrofitted with CCS & 217 & 337 & -0.0062 & +0.00126 & +0.00004 & 0 \\
\hline $\mathrm{CO}_{2}$ capture water use & $+80 \%$ & $+40 \%$ & +0.0053 & -0.00052 & -0.00004 & 0 \\
\hline Aquaculture use & Unchanged & $+20 \%$ & -0.0043 & +0.00324 & +0.00008 & 0 \\
\hline Industrial use & Unchanged & $+20 \%$ & -0.0022 & +0.00014 & +0.00014 & 0 \\
\hline Population growth & Medium & High & -0.0022 & +0.00041 & +0.00010 & 0 \\
\hline Population growth & Medium & Low & +0.0014 & -0.00037 & -0.00011 & 0 \\
\hline Brine extraction and use & Yes & No & -0.0013 & +0.00005 & 0.00000 & 0 \\
\hline Livestock use & Unchanged & $+20 \%$ & -0.0011 & +0.00017 & +0.00005 & 0 \\
\hline Brine: $\mathrm{CO}_{2}$ volume ratio & $1: 1$ & $0.5: 1$ & -0.0007 & +0.00003 & 0.00000 & 0 \\
\hline Max distance to aquifer & $100 \mathrm{~km}$ & $250 \mathrm{~km}$ & +0.0005 & -0.00002 & 0.00000 & 0 \\
\hline Mining use & Unchanged & $+20 \%$ & -0.0003 & +0.00008 & +0.00003 & 0 \\
\hline Max distance to aquifer & $100 \mathrm{~km}$ & $25 \mathrm{~km}$ & -0.0002 & +0.00001 & 0.00000 & 0 \\
\hline CCS energy penalty & $35 \%$ & $20 \%$ & -0.0001 & +0.00001 & 0.00000 & 0 \\
\hline
\end{tabular}




\section{Conclusions}

In this analysis we have considered how CCS implementation affects water stress, and identified areas in which water stress may limit CCS implementation. Because water stress varies from place to place, we have conducted a geospatial analysis detailing the county-level balances of water supply and demand across the contiguous United States. Our focus has been to identify and understand the major sources of uncertainty and variation regarding the water-CCS nexus.

We find that CCS can strongly affect freshwater supply and demand in specific locations, but overall it has a moderate effect on water balances. Water supply changes due to inter-annual variability and longerterm climate change effects are the most significant sources of water stress. The use of extracted brine to overcome local water constraints may reduce local water stress compared to what would be possible without brine extraction. The importance of extracted brine increases as the water supply becomes more limited, a condition that is increasingly likely to occur as future climate becomes more unstable.

There are several issues that introduce uncertainty and may affect the results of this analysis. For example, the WaSSi water supply model does not consider water storage (e.g. in reservoirs), which could moderate inter-annual variability in water supply and thus reduce the differences in results between average and minimum water supply years. Spatially-explicit data on US dams are available (US Corps of Engineers 2015) and could be added to this analysis to improve validity of results. Furthermore, the contributions of return flow to total water supply are held constant in our modeling, though return flow quantities may vary due to future changes in water use efficiency.

We have used regional climate projections from the CSIRO MK2 climate model. To determine the significance of the particular climate model, updated projections from other climate models could be compared. In all cases, however, the definitive effects of future climate change on water supply will be uncertain, and include both spatial variation and temporal variation. In this analysis we have defined the minimum annual water supply for each HUC unit as the lowest value among the 9-year sampling period. This definition represents an extreme case of drought across the entire country. In practice, drought in some HUC units will likely be moderated by average or above-average water supply in other, upstream HUC units. Sampling each county separately would account for this factor, though some measure of regional correlation in weather and climate should be expected.

Although we consider only one management option for extracted brine-desalination for use as freshwater-a range of other potential uses for brine exist such as mineral recovery, algae ponds, and deicing salt production (Breunig et al. 2013). Extracted brine can also potentially be used directly for power plant cooling without desalination (Kobos et al. 2011). In addition, brine extraction could have negative effects on water balances if freshwater is needed for dilution. The significance of these potentials should be explored in future work.

In a more comprehensive analysis, water stress could be considered as a proxy for the cost or value of water. Local water stress could be used as a criterion for weighing the need or likelihood of applying various options. For example, in a water-stressed area, water will be more valuable and it may be more economically feasible to use brine as a water source. The attractiveness of using desalinated brine as a freshwater source would likely depend on the water stress of a region. Areas with greater water stress may be more likely to transport $\mathrm{CO}_{2}$ and brine across further distances. The potential impacts on water balance of dry cooling methods, which are generally more expensive than water-based cooling methods, could also be elaborated. 
This analysis is offered as an initial exploration of the potential local water implications of CCS deployment. Despite the uncertainties involved, we have identified overall trends that appear to be robust. We have modelled the system drivers for county-level water balance, and quantified the effects that CCS and brine desalination may have on local water stress. Variation in water supply due to inter-annual variability and projected climate change are by far the most significant sources of water stress change, though CCS can also strongly affect water supply and demand in specific counties. As the local water supply becomes more limited, the additional freshwater supply made available from desalinated brine becomes more important.

\section{Acknowledgement}

Lawrence Berkeley National Laboratory is supported by the U.S. Department of Energy under Contract No. DE-AC02-05CH11231.

\section{References}

Aines RD, Wolery TJ, Bourcier WL, Wolfe T, Hausmann C. 2011. Fresh water generation from aquifer pressured carbon storage: Feasibility of treating saline formation waters. Energy Procedia 4: 22692276.

Bachu S, Adams JJ. 2003. Sequestration of $\mathrm{CO}_{2}$ in geological media in response to climate change: Capacity of deep saline aquifers to sequester $\mathrm{CO}_{2}$ in solution. Energy Conversion and Management 44(20): 3151-3175.

Bourcier W. 2011. Use of formation fluids produced at CCS sites for power plant cooling. Presented at 10th Annual Conference on Carbon Capture and Sequestration, May 2-5, Pittsburgh PA.

Bourcier WL, Wolery TJ, Haussmann C, Buscheck TA, Aines RD. 2011. A preliminary cost and engineering estimate for desalinating produced formation water associated with carbon dioxide capture and storage. International Journal of Greenhouse Gas Control 5(5): 1319-1328.

Breunig HM, Birkholzer JT, Borgia A, Oldenburg CM, Price PN, McKone TE. 2013. Regional evaluation of brine management for geologic carbon sequestration. International Journal of Greenhouse Gas Control 14: 39-48.

Brown TC. 2000. Projecting U.S. freshwater withdrawals. Journal of Water Resources Research 36(3):769-780.

Buscheck TA, Sun Y, Chen M, Hao Y, Wolery TJ, Bourcier WL, Court B, Celia MA, Friedmann SJ, Aines RD. 2012. Active $\mathrm{CO}_{2}$ reservoir management for carbon storage: Analysis of operational strategies to relieve pressure buildup and improve injectivity. International Journal of Greenhouse Gas Control 6: 230-245.

Corsten M, Ramirez A, Shen L, Koornneef J, Faaij A. 2013. Environmental impact assessment of CCS chains: Lessons learned and limitations from LCA literature. International Journal of Greenhouse Gas Control 13: 59-71.

Coulson DP, Joyce LA, Price DT, McKenney DW. 2010. Data product for the RPA 2010 Climate Scenarios for the conterminous United States at the county spatial scale using SRES scenario B2 and PRISM climatology. Fort Collins, CO: U.S. Department of Agriculture, Forest Service, Rocky Mountain Research Station.

Court B, Celia MA, Nordbotten JM, Elliot TR. 2011. Active and integrated management of water resources throughout $\mathrm{CO}_{2}$ capture and sequestration operations. Energy Procedia 4: 4221-4229.

EIA (US Energy Information Agency). 2011. Annual Energy Outlook 2011. Web-accessed at http://www.eia.gov/forecasts/archive/aeo11/ 
Ellis M, Dillich S, Margolis N. 2001. Industrial Water Use and Its Energy Implications. Energetics, Incorporated and U.S. Department of Energy, Washington, DC.

Hasan MMF, Boukouvala F, First EL, Floudas CA. 2014. Nationwide, regional, and statewide $\mathrm{CO}_{2}$ capture, utilization, and sequestration supply chain network optimization. Industrial \& Engineering Chemistry Research 53: 7489-7506.

Herzog HJ. 2011. Scaling up carbon dioxide capture and storage: From megatons to gigatons. Energy Economics 33(4): 597-604.

IEA (International Energy Agency). 2012. CCS Retrofit: Analysis of the Globally Installed Coal-Fired Power Plant Fleet. Web-accessed at http://www.iea.org/

IEA (International Energy Agency). 2013. Technology Roadmap: Carbon Capture and Storage. Webaccessed at http://www.iea.org/

IPCC (Intergovernmental Panel on Climate Change). 2000. Special Report on Emission Scenarios. Webaccessed at http://www.ipcc.ch/

IPCC (Intergovernmental Panel on Climate Change). 2005. Special Report on Carbon Dioxide Capture and Storage. Web-accessed at http://www.ipcc.ch/

IPCC (Intergovernmental Panel on Climate Change). 2014. Climate Change 2014: Mitigation of Climate Change. Contribution of Working Group III to the Fifth Assessment Report. Web-accessed at http://www.ipcc.ch/

Kenny JF, Barber NL, Hutson SS, Linsey KS, Lovelace JK, Maupin MA. 2009. Estimated use of water in the United States in 2005. US Geological Survey Circular 1344.

Khoo HH, Tan RBH. 2006. Life cycle investigation of $\mathrm{CO}_{2}$ recovery and sequestration. Environmental Science \& Technology 40: 4016-4024.

Kobos PH, Cappelle MA, Krumhansl JL, Dewers TA, McNemar A, Borns DJ. 2011. Combining power plant water needs and carbon dioxide storage using saline formations: Implications for carbon dioxide and water management policies. International Journal of Greenhouse Gas Control 5(4): 899-910.

Macknick J, Newmark R, Heath G, Hallett KC. 2011. A Review of Operational Water Consumption and Withdrawal Factors for Electricity Generating Technologies. Technical Report NREL/TP-6A2050900; National Renewable Energy Laboratory, Golden, CO.

MIT (Massachusetts Institute of Technology). 2012. Retrofitting of Coal-Fired Power Plants for $\mathrm{CO}_{2}$ Emissions Reductions. Web-accessed at http://mitei.mit.edu/publications/reports-studies/retrofittingcoal-fired-power-plants-co2-emissions-reductions

NETL (National Energy Technology Laboratory). 2010a. Carbon Sequestration Atlas of the United States and Canada. National Energy Technology Laboratory; US Department of Energy. Web-accessed at http://www.netl.doe.gov/

NETL (National Energy Technology Laboratory). 2010b. Estimating Freshwater Needs to Meet Future Thermoelectric Generation Requirements: 2010 Update. Report DOE/NETL-400/2010/1339. National Energy Technology Laboratory, Morgantown, WV.

NETL (National Energy Technology Laboratory). 2012. National Carbon Sequestration Database and Geographic Information System. National Energy Technology Laboratory; US Department of Energy. Web-accessed at http://www.netl.doe.gov/

Roy SB, Summers KV, Goldstein RA. 2004. Water sustainability in the United States and cooling water requirements for power generation. Journal of Contemporary Water Research and Education 127(1): Article 12.

Sathre R, Cain J, Chester M, Masanet E. 2011. The role of Life Cycle Assessment in identifying and reducing environmental impacts of CCS. Proceeding of 10th Annual Conference on Carbon Capture and Sequestration, Pittsburgh, USA.

Sathre R, Chester M, Cain J, Masanet E. 2012. A framework for environmental assessment of $\mathrm{CO}_{2}$ capture and storage systems. Energy 37(1): 540-548. 
Schakel W, Pfister S, Ramírez A. 2015. Exploring the potential impact of implementing carbon capture technologies in fossil fuel power plants on regional European water stress index levels. International Journal of Greenhouse Gas Control 39: 318-328.

Solley WB, Pierce RR, Perlman HA. 1998. Estimated use of water in the United States in 1995. US Geological Survey Circular 1200.

Strzepek K, Yohe G, Neumann J, Boehlert B. 2010. Characterizing changes in drought risk for the United States from climate change. Environmental Research Letters 5:044012.

Sun G, McNulty SG, Moore Myers JA, Cohen EC. 2008. Impacts of climate change, population growth, land use change, and groundwater availability on water supply and demand across the conterminous U.S. Watershed Update 6(2).

Talati S, Zhai H, Morgan MG. 2014. Water impacts of $\mathrm{CO}_{2}$ emission performance standards for fossil fuel-fired power plants. Environmental Science \& Technology 48(20): 11769-11776.

Tidwell VC, Malczynski LA, Kobos PH, Klise GT, Shuster E. 2013. Potential impacts of electric power production utilizing natural gas, renewables and carbon capture and sequestration on U.S. freshwater resources. Environmental Science \& Technology 47(15): 8940-8947.

US Army Corps of Engineers. 2015. National Inventory of Dams. Web-accessed at http://nid.usace.army.mil

Ventyx. 2012. Velocity Suite Database System.

Wolery TJ, Aines RD, Hao Y, Bourcier W, Wolfe T, Haussman C. 2009. Fresh Water Generation from Aquifer-Pressured Carbon Storage: Annual Report FY09. Report LLNL-TR-420857. Lawrence Livermore National Laboratory, Livermore, CA.

Zarnoch SJ, Cordell HK, Betz CJ, Langner L. 2010. Projecting County-Level Populations Under Three Future Scenarios: A Technical Document Supporting the Forest Service 2010 RPA Assessment. Technical Report SRS-128. US Department of Agriculture Forest Service, Southern Research Station, Asheville, NC.

Zhai H, Rubin ES. 2010. Performance and cost of wet and dry cooling systems for pulverized coal power plants with and without carbon capture and storage. Energy Policy 38(10): 5653-5660.

Zhai H, Rubin ES, Versteeg PL. 2011. Water use at pulverized coal power plants with postcombustion carbon capture and storage. Environmental Science and Technology 45(6): 2479-2485.

Zhou G, Sun G, Wang X, Zhou C, McNulty SG, Vose JM, Amatya DM. 2008. Estimating forest ecosystem evapotranspiration at multiple temporal scales with a dimension analysis approach. Journal of the American Water Resources Association 44(1): 208-221. 